05.3;05.4; 15.2

\title{
Мартенситные превращения и эффект памяти формы биосовместимых сплавов TiNiMoAl
}

\author{
(C) А.Н. Моногенов ${ }^{1}$, В.Э. Гюнтер ${ }^{1}$, Е.С. Марченко ${ }^{1}$, С.Г. Аникеев ${ }^{1}$, В.Н. Ходоренко ${ }^{1}$, \\ А.А. Радкевич ${ }^{2}$ В.Ю. Подгорный ${ }^{3}$, Н.В. Артюхова ${ }^{1}$ \\ ${ }^{1}$ Томский государственный университет, Томск, Россия \\ ${ }^{2}$ Научно-исследовательский институт медицинских проблем Севера ФИЦ КНЦ СО РАН, \\ Красноярск, Россия \\ ${ }^{3}$ Красноярский государственный медицинский университет, Красноярск, Россия \\ E-mail: monogenov@mail.ru
}

Поступило в Редакцию 22 сентября 2020 г.

В окончательной редакции 10 декабря 2020 г.

Принято к публикации 10 декабря 2020г.

\begin{abstract}
Проведено исследование мартенситных превращений и характеристик эффекта памяти формы сплавов медицинского назначения (TH-10), легированных алюминием до 4 at.\% по разрезу TiNiMo-TiMeMo. Влияние на температуры начала и конца прямого и обратного мартенситного превращения, а также на аналогичные характеристики под нагрузкой алюминий оказывает довольно плавно, что позволяет использовать легирование алюминием как метод управления температурным интервалом формоизменения при эффекте памяти формы.
\end{abstract}

Ключевые слова: никелид титана, мартенситные превращения, эффект памяти формы, биосовместимые материалы.

DOI: 10.21883/PJTF.2021.06.50757.18555

Разработка сплавов на основе $\mathrm{TiNi}$ медицинского назначения с необходимым комплексом физико-механических характеристик, управляемым эффектом памяти формы и минимальным иммунным откликом со стороны окружающих тканей организма является актуальной задачей. Влияние легирования различными элементами на мартенситные превращения (МП) было классифицировано [1,2]. Такие химические элементы, как $\mathrm{Cu}$, $\mathrm{Co}, \mathrm{Fe}, \mathrm{Mo}, \mathrm{Rh}, \mathrm{Mn}, \mathrm{Nb}, \mathrm{Sc}, \mathrm{Y}, \mathrm{Al}$ и др., снижают температуры МП, другие (Au, Ag, Dy, Hf, Pt, Pd, Zr) повышают эти характеристики [3-5]. Тройные системы TiNiAl c содержанием 2 at.\% Al имеют два перехода: $B 2 \leftrightarrow R \leftrightarrow B 19^{\prime}$ [6]. В сплавах TiNiAl при концентрации $\mathrm{Al}$, большей чем 5 at.\%, МП не завершаются полностью вплоть до $-196^{\circ} \mathrm{C}$ [7]. Известно, что система TiNiAl обладает высокими прочностными характеристиками и имеет повышенную коррозионную стойкость, в частности, в агрессивных средах организма (по сравнению с системой TiNi) [8,9]. Поэтому система TiNiAl является особенно перспективной с точки зрения применения данных сплавов в медицине. В качестве основы для проведения легирования Al был выбран хорошо зарекомендовавший себя на практике и запатентованный сплав медицинского назначения ТН-10 следующего состава: $\mathrm{Ti}_{49.9} \mathrm{Ni}_{49.9} \mathrm{Mo}_{0.2}$. Необходимость добавки молибдена в бинарный сплав TiNi вызвана сложностью при обработке и изготовлении серийно выпускаемых конструкций для практического использования в медицине. Легирование молибденом никелида титана облегчает прокатку, ковку, волочение (проволоки). Исследование четверных спла- вов TiNiMoAl представляет не только научный, но и практический интерес [10].

Цель настоящей работы - определить влияние добавки алюминия в шихту сплава $\mathrm{Ti}_{49.9} \mathrm{Ni}_{49.9} \mathrm{Mo}_{0.2}$ на характеристические температуры МП и параметры эффекта памяти формы.

Сплавы были получены в индукционной печи марки ИСВ-0.004 ПИ М1 в атмосфере инертного газа (аргона). Далее из слитка вырезались образцы размером $50 \times 1 \times 1 \mathrm{~mm}$, которые отжигались в электровакуумной печи марки СНВЭ-1.31/15-И4 в вакууме $10^{-4} \mathrm{~Pa} \mathrm{при}$ температуре $850^{\circ} \mathrm{C}$ в течение $2 \mathrm{~h}$. Эффект памяти формы (ЭПФ) был изучен с помощью испытательного комплекса „Инстрон 3369“ с климатической камерой, постоянно действующая нагрузка вызывала внутренние напряжения $20 \mathrm{MPa}$. Исследования микроструктуры были проведены на микроскопе OLYMPUS GX71. На растровом электронном микроскопе PHILIPS SEM 515 (EDAX ECON IV) проведен элементный анализ. Рентгеноструктурные исследования сплавов были выполнены на дифрактометpe XRD 6000. Легирование Al проводилось по разрезу TiNiMo-TiMeMo от 0 до 4 at.\%.

Установлено, что все составы исследуемых сплавов имеют близкую микроструктуру, различающуюся лишь количеством межзеренной фазы (рис. 1). Методом секущих определены размеры зерен, которые варьируются от 3 до $158 \mu \mathrm{m}$, средний размер зерна составляет $29 \mu \mathrm{m}$. Помимо матричной фазы TiNi (фаза 1) по границам зерен присутствует вторичная фаза, размер последней составляет $1-4 \mu \mathrm{m}$, при этом средний размер фазы 2 составляет $2 \mu \mathrm{m}$. 

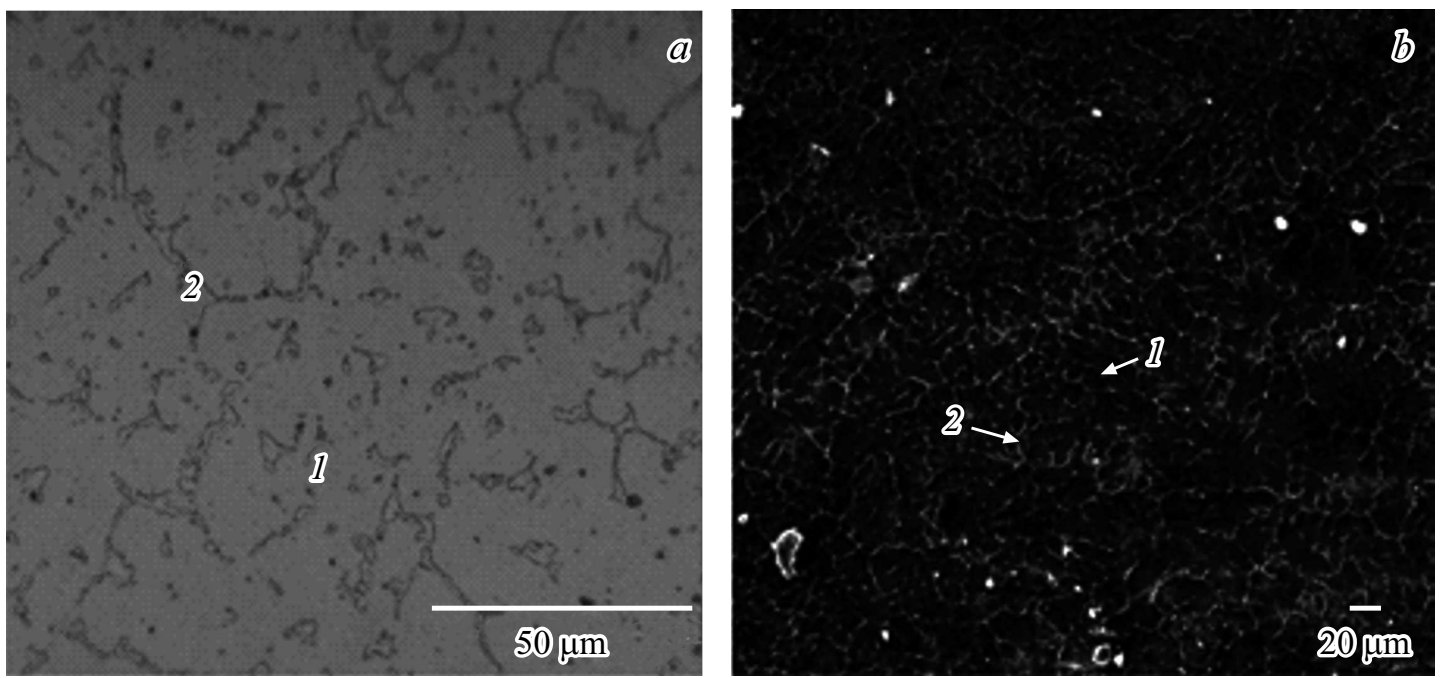

Рис. 1. Микроструктура сплава $\mathrm{Ti}_{49.9} 9 \mathrm{Ni}_{45.9} \mathrm{Mo}_{0.2} \mathrm{Al}_{4} . a-$ изображение с оптического микроскопа, $b-$ изображение, полученное с помощью растрового электронного микроскопа с использованием детектора вторичных электронов $(1-$ матричная фаза TiNi, 2 - вторичная фаза на основе $\left.\mathrm{Ti}_{2} \mathrm{Ni}\right)$.

Таблица 1. Элементный анализ сплавов TiNiMoAl (в at.\%)

\begin{tabular}{c|c|c|c|c|c|r|r|r}
\hline \multirow{2}{*}{ Элемент } & \multicolumn{2}{|c|}{$\mathrm{Ti}_{49.9} \mathrm{Ni}_{49.9} \mathrm{Mo}_{0.2}$} & \multicolumn{2}{c|}{$\mathrm{Ti}_{49.9} \mathrm{Ni}_{48.9} \mathrm{Mo}_{0.2} \mathrm{Al}_{1}$} & \multicolumn{2}{|c|}{$\mathrm{Ti}_{49.9} \mathrm{Ni}_{47.9} \mathrm{Mo}_{0.2} \mathrm{Al}_{2}$} & \multicolumn{2}{|c}{$\mathrm{Ti}_{49.9} \mathrm{Ni}_{45.9} \mathrm{Mo}_{0.2} \mathrm{Al}_{4}$} \\
\cline { 2 - 9 } & Фаза 1 & Фаза 2 & Фаза 1 & Фаза 2 & Фаза 1 & Фаза 2 & Фаза 1 & Фаза 2 \\
\hline $\mathrm{Ti}$ & 47.17 & 57.32 & 46.35 & 55.08 & 44.36 & 56.21 & 51.76 & 55.84 \\
$\mathrm{Ni}$ & 52.83 & 42.68 & 53.15 & 44.21 & 55.02 & 42.28 & 47.19 & 40.26 \\
$\mathrm{Al}$ & 0 & 0 & 0.50 & 0.71 & 0.62 & 1.51 & 1.05 & 3.90
\end{tabular}

Таблица 2. Рентгеноструктурный анализ сплавов TiNiMoAl

\begin{tabular}{|c|c|c|c|}
\hline Сплав & $\begin{array}{c}\text { Фазовый } \\
\text { состав }\end{array}$ & $\begin{array}{c}\text { Содержание, } \\
\text { at.\% }\end{array}$ & Параметры решетки, $\AA$ \\
\hline $\mathrm{Ti}_{49.9} \mathrm{Ni}_{49.9} \mathrm{Mo}_{0.2}$ & $\begin{array}{c}\mathrm{TiNi}, B 2 \\
\mathrm{Ti}_{2} \mathrm{Ni}\end{array}$ & $\begin{array}{l}90 \\
10\end{array}$ & $\begin{array}{l}a=3.0429 \\
a=11.219\end{array}$ \\
\hline $\mathrm{Ti}_{49.9} \mathrm{Ni}_{48.9} \mathrm{Mo}_{0.2} \mathrm{Al}_{1}$ & $\begin{array}{c}\mathrm{TiNi}(\mathrm{Al}), B 2 \\
\mathrm{TiNi}(\mathrm{Al}), B 19^{\prime} \\
\mathrm{Ti}_{2} \mathrm{Ni}(\mathrm{Al})\end{array}$ & $\begin{array}{c}76 \\
4 \\
20\end{array}$ & $\begin{array}{c}a=3.027 \\
a=4.526, b=4.197, c=2.9153, \beta=97.0014^{\circ} \\
a=11.373\end{array}$ \\
\hline $\mathrm{Ti}_{49.9} \mathrm{Ni}_{47.9} \mathrm{Mo}_{0.2} \mathrm{Al}_{2}$ & $\begin{array}{l}\operatorname{TiNi}(\mathrm{Al}), B 2 \\
\mathrm{TiNi}(\mathrm{Al}), B 19^{\prime} \\
\mathrm{Ti}_{2} \mathrm{Ni}(\mathrm{Al})\end{array}$ & $\begin{array}{r}66 \\
5 \\
29\end{array}$ & $\begin{array}{c}a=3.0229 \\
a=4.5858, b=4.1501, c=2.9128, \beta=95.8^{\circ} \\
a=11.3195\end{array}$ \\
\hline
\end{tabular}

Методом рентгеноспектрального микроанализа установлен элементный состав основной и вторичной фаз (табл. 1). Фаза 1 (TiNi) содержит помимо основных элементов ( $\mathrm{Ti}, \mathrm{Ni}$ ) алюминий (табл. 1). Отсутствие молибдена во всех образцах объясняется его изначально незначительным расчетным количеством (0.2 at.\%) и погрешностью самой методики определения содержания химических элементов.

Рентгеноструктурный анализ сплава $\mathrm{Ti}_{49.9} \mathrm{Ni}_{48.9} \mathrm{Mo}_{0.2} \mathrm{Al}_{1}$ показал наличие только двух фаз: $\mathrm{TiNi}(80 \%)$ и $\mathrm{Ti}_{2} \mathrm{Ni}(20 \%)$ (табл. 2). С ростом содержания алюминия соотношение основной фазы и фазы 2 смещается в сторону $\mathrm{Ti}_{2} \mathrm{Ni}(\mathrm{Al})$. Таким образом, фаза 2 может быть идентифицирована как фаза на основе соединения $\mathrm{Ti}_{2}(\mathrm{Ni}, \mathrm{Al})$, в которое входит около $1 \% \mathrm{Al}$. При легировании алюминием вместо никеля параметр решетки B2-фазы уменьшается (табл. 2). Авторы предполагают, что алюминий способствует образованию фазы на основе $\mathrm{Ti}_{2} \mathrm{Ni}$ и входит в состав основной фазы TiNi.

Установлено, что температуры прямого и обратного МП, такие как $M_{s}, M_{f}, A_{s}, A_{f}$, с ростом концентрации $\mathrm{Al}$ снижаются (рис. 2,a). Общий температурный интервал 

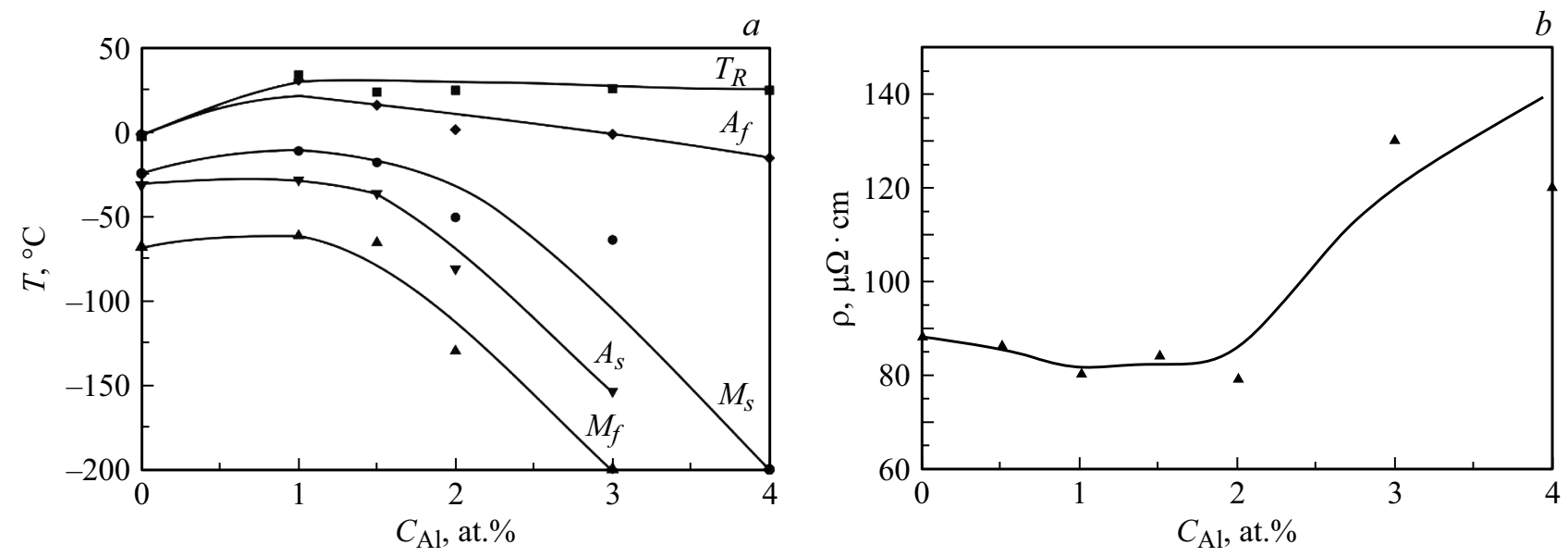

Рис. 2. Диаграмма мартенситных превращений $(a)$ и концентрационная зависимость удельного электросопротивления $(b)$ сплавов системы $\mathrm{TiNi}_{1-x} \mathrm{MoAl}_{x}$ при $t=25^{\circ} \mathrm{C}$.
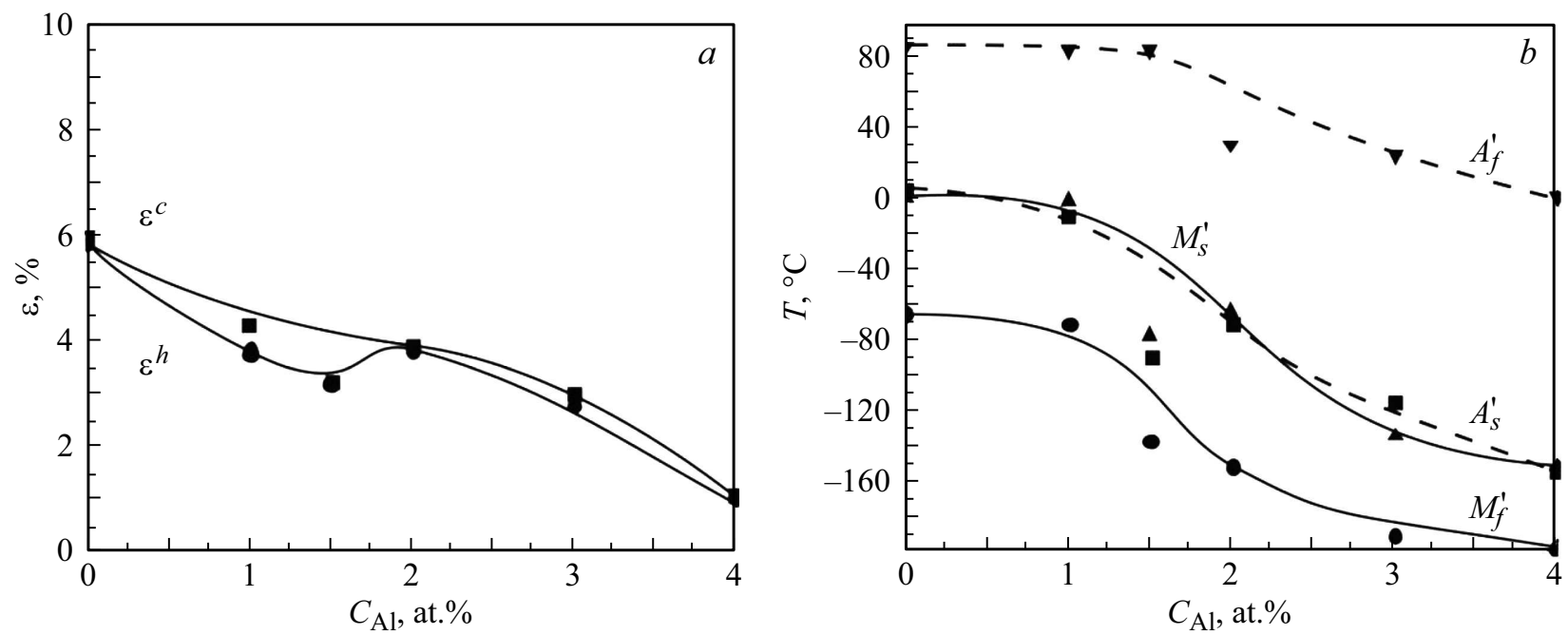

Рис. 3. Концентрационные зависимости накопленной при ЭПФ деформации системы $\mathrm{TiNi}_{1-x} \mathrm{MoAl}_{x}(a)$ и температурные параметры ЭПФ под нагрузкой $(b) . \varepsilon^{c}-$ обратимая деформация при охлаждении, $\varepsilon^{h}-$ обратимая деформация при нагреве, $M_{s}^{\prime}$ - температура начала формоизменения при охлаждении, $M_{f}^{\prime}$ - температура конца формоизменения при охлаждении, $A_{s}^{\prime}-$ температура начала формоизменения при нагреве, $A_{f}^{\prime}$ - температура конца формоизменения при нагреве.

МП $M_{f}-A_{f}$ сплавов $\mathrm{Ti}_{49.9} \mathrm{Ni}_{49.9-x} \mathrm{Mo}_{0.2} \mathrm{Al}_{x}$ расширяется. Температура перехода ромбоэдрической $R$-фазы в моноклинную $B 19^{\prime}\left(M_{S}\right)$ сильно зависит от концентрации алюминия, в то же время температура превращения высокотемпературной фазы $B 2$ в $R$-фазу $\left(T_{R}\right)$ от концентрации алюминия не зависит. Влияние на температуры $M_{s}$ и $M_{f}$ алюминий оказывает плавно, что позволяет использовать легирование алюминием для смещения интервалов МП и управлять температурным интервалом формоизменения при эффекте памяти формы. Плавное снижение характеристических температур и расширение температурного интервала МП, вероятно, связаны со снижением концентрации титана в матричной фазе. Незначительное повышение температуры $T_{R}$ с ростом концентрации алюминия, вероятно, является следствием внедрения атомов алюминия в матричную фазу $B 2$. По- скольку алюминий по своему атомному радиусу ближе к атомам титана, его внедрение в подрешетку никеля B2-фазы вызывает большие внутренние напряжения, которые, согласно уравнению Клапейрона-Клаузиуса, смещают температуру равновесия аустенитной и мартенситной фаз в сторону более высоких температур. Удельное электросопротивление сплавов $\mathrm{TiNi}_{1-x} \mathrm{MoAl}_{x}$ с возрастанием содержания Al до 2 at.\% незначительно снижается, а затем резко возрастает (рис. 2,b). Авторы предполагают, что при легировании 2 at.\% $\mathrm{Al}$ сплавов TiNiMo накапливается некоторое критическое количество дефектов, которое резко повышает удельное электросопротивление.

Величина накопленной деформации ЭПФ как в ходе охлаждения, так и в ходе нагрева уменьшается с увеличением $C_{\mathrm{Al}}$ (рис. $\left.3, a\right)$. Легирование сплава (ТН-10) алю- 
минием приводит к уширению температурных интервалов восстановления формы $A_{f}^{\prime}-M_{f}^{\prime}$ (рис. $3, b$ ). Величина остаточной деформации близка к нулю. Установлено, что легирование алюминием системы $\mathrm{Ti}_{49.9} \mathrm{Ni}_{49.9-x} \mathrm{Mo}_{0.2} \mathrm{Al}_{x}$ приводит к сдвигу температур начала формоизменения $M_{s}^{\prime}$ вплоть до $125^{\circ} \mathrm{C}$ относительно исходного сплава в сторону отрицательных температур, при этом температура МП $B 2 \rightarrow R$, полученная по началу подъема кривой удельного электросопротивления, остается постоянной. Сплавы системы $\mathrm{TiNi}_{1-x} \mathrm{MoAl}_{x}$ проявляют ЭПФ под нагрузкой, однако значение максимальной обратимой деформации снижается с 5.8 до 1\% с ростом содержания алюминия. Причины высокой обратимой деформации сплава $\mathrm{Ti}_{49.9} \mathrm{Ni}_{49.9} \mathrm{Mo}_{0.2}$ кроются в высокой пластичности превращения, связанной с сильным размягчением упругих констант решетки B2-фазы в преддверии превращения в мартенситную фазу.

Сплавы системы $\mathrm{TiNi}_{1-x} \mathrm{MoAl}_{x}$ имеют перспективу практического применения, так как МП при концентрации алюминия до 1.5 at.\% находятся на приемлемом уровне температур, ЭПФ проявляется и характеризуется величиной обратимой деформации до $4 \%$.

\section{Финансирование работы}

Результаты получены в ходе выполнения государственного задания Минобрнауки России (проект № 0721-2020-0022).

\section{Конфликт интересов}

Авторы заявляют, что у них нет конфликта интересов.

\section{Список литературы}

[1] Медицинские материалы и имплантаты с памятью бормы, под ред. В.Э. Гюнтера (Изд-во МИЦ, Томск, 2011), т. 1, с. 194-207.

[2] Е.С. Марченко, Г.А. Байгонакова, В.Э. Гюнтер, А.А. Клопотов, ЖТФ, $90 \quad$ (5), $769 \quad$ (2020). DOI: 10.21883/JTF.2020.05.49177.342-18 [Пер. версия: 10.1134/S1063784220050175].

[3] Е.С. Марченко, Г.А. Байгонакова, В.Э. Гюнтер, Письма в ЖТФ, 44 (16), $96 \quad$ (2018). DOI: 10.21883/PJTF.2018.16.46482.17309 [Пер. версия: 10.1134/S1063785018080254].

[4] X. Li., X.-Q. Tu, B.-Q. Liu, J.-M. Song, W. Luo, Y. Lei, G.-A. Sun, B. Chen, Q.-M. Hu, J. Alloys Compd., 706, 260 (2017). https://doi.org/10.1016/j.jallcom.2017.02.174

[5] Y.V. Kudryavtsev, E.L. Semenova, Powder Metall. Met. Ceram., 48 (11-12), 700 (2009). https://doi.org/10.1007/s11106-010-9188-6

[6] T. Kurita, H. Matsumoto, K. Sakamoto, K. Tanji, H. Abe, J. Alloys Compd., 396 (1-2), 193 (2005). https://doi.org/10.1016/j.jallcom.2004.12.032

[7] L.J. Meng, Y. Li, X.Q. Zhao, J. Xu, H.B. Xu, Intermetallics, 15 (5-6), 814 (2007).

https://doi.org/10.1016/j.intermet.2006.10.038
[8] M.J. Garcia-Ramirez, R. Lopez-Sesenes, I. Rosales-Cadena, J.G. Gonzalez-Rodriguez, J. Mater. Res. Technol., 7 (3), 223 (2017). https://doi.org/10.1016/j.jmrt.2017.07.003

[9] J. Zhu, Q. Zeng, T. Fu, Corros. Rev., 37 (6), 539 (2019). https://doi.org/10.1515/corrrev-2018-0104

[10] Shape memory implants, ed. by L. Yahia (Springer-Verlag, Berlin-Heidelberg, 2000), p. 94-102. DOI: $10.1007 / 978-3-642-59768-8$ 